\title{
LA CONTRIBUCIÓN ECONÓMICA DE LAS EXPORTACIONES EN MÉXICO: UN ACERCAMIENTO DESDE LAS FINANZAS ESTATALES, 1880-1926
}

\author{
THE ECONOMIC CONTRIBUTION \\ OF EXPORTS IN MEXICO: \\ AN APPROACH FROM THE STATES' \\ FINANCES, 1880-1926
}

\author{
Sandra Kuntz Ficker* \\ El Colegio de México, ciudad de México, México, <skuntz@colmex.mx>
}

\begin{abstract}
Resumen: Este trabajo ofrece un acercamiento inicial al estudio de la contribución de las exportaciones mexicanas a las finanzas públicas de los estados durante la primera era exportadora. Para ello, la autora aprovecha la información disponible sobre las finanzas estatales para algunos años dentro del periodo y la analiza mediante un procedimiento con dos grados distintos de aproximación. Por un lado, compara los ingresos ordinarios de los estados a fin de contrastar entre estados exportadores y no exportadores y por esa vía valorar el papel de las exportaciones en la prosperidad de las finanzas estatales. Por el otro, compara los ingresos originados en actividades exportadoras en los diferentes estados, a fin de estimar la contribución directa de las exportaciones al erario de cada uno de ellos.
\end{abstract}

Palabras clave: exportaciones; finanzas estatales; era exportadora; enlace fiscal.

\begin{abstract}
This paper provides a preliminary approach to the study of the contribution of Mexico's exports to the states' public finances during the first export era. In order to do so, it analyses the available information on state finances for some years within the period by means of a twofold procedure. On the one hand, a comparison among the ordinary income of the different states is provided, with the aim of contrasting between exporter and non-exporter states and assessing the importance of exports in the prosperity of state finances. On the other hand, a comparison of the income generated in export activities in all the states is provided, with the purpose of evaluating the direct contribution of exports to each of the states' treasuries.
\end{abstract}

Key words: exports; state finances; export era; fiscal linkage.

Fecha de recepción: mayo de 2013. Fecha de aceptación: agosto de 2013.

\footnotetext{
* Una versión preliminar de este trabajo fue presentada como ponencia en el II Congreso Latinoamericano de Historia Económica, realizado en la ciudad de México del 3 al 5 de febrero
}

Am. Lat. Hist. Econ., año 21, núm. 2, mayo-agosto, 2014, pp. 7-39 


\section{INTRODUCCIÓN}

$\mathrm{E}$ n este trabajo nos proponemos ofrecer un primer acercamiento a un problema que ha sido sólo parcialmente abordado en estudios regionales, sectoriales o de empresa, pero que hasta hoy no ha merecido una aproximación más general: el de la contribución de las exportaciones a las finanzas de los estados a lo largo de la primera era exportadora del México moderno. La tradición estructuralista suele imprimir un tono negativo a la valoración sobre el enlace fiscal de las exportaciones, atribuyéndole el significado de una compensación parcial por la extracción (muchas veces vista como indiscriminada) de riqueza en unidades productivas que operaban como enclaves dentro de la economía nacional. En otra parte hemos demostrado que la noción de enclave explica pobremente la dinámica de las actividades exportadoras, pues por lo general estas poseían múltiples conexiones con la economía de las regiones en que se asentaban, imprimiéndole un mayor dinamismo. ${ }^{1}$ Para lo que aquí nos concierne, esta revaloración positiva del sector exportador implica proponer que el enlace fiscal no era una compensación parcial (por la pérdida que representaría la riqueza extraída sin la debida retribución) sino una contribución adicional a la economía de las entidades productoras. Cuando los hubo, estos ingresos enriquecieron las finanzas estatales y a veces las ayudaron a escapar de su precaria situación, ya fuera que luego se invirtieran productivamente o simplemente generaran enlaces de consumo mediante el gasto, incrementando la demanda agregada.

Asimismo, esta revaloración positiva otorga significación al análisis de la diversa capacidad de los gobiernos estatales para imponer y recaudar gravámenes sobre el sector exportador. En un trabajo anterior hemos destacado la importancia de los enlaces fiscales estatales de la mayor parte de las actividades de exportación. No obstante, la perspectiva desde la cual se abordó el estudio (un análisis por productos, no por estados o regiones) no permitía una sistematización de los resultados en términos de agrupación o comparación entre las distintas entidades. Este trabajo confirma los resultados de esa investigación más amplia en términos de revalorar positivamente la contribución económica de las exportaciones. No obstante, además de privilegiar la perspectiva estatal (y no por productos), el presente trabajo ofrece datos de fuentes homogéneas para los mismos años dentro de la era exportadora, lo que permite un análisis transversal

de 2010. Agradezco los comentarios que en esa ocasión recibí de José Díaz, Mauricio Folchi, Antonio Tena y José Antonio Ocampo, así como a los de tres evaluadores anónimos de la revista por sus valiosas observaciones. Todos fueron muy útiles para la elaboración de esta versión final. Naturalmente, los contenidos son responsabilidad mía.

${ }^{1}$ Kuntz, Exportaciones, 2010. 
del fenómeno que se desea destacar. Ello, al mismo tiempo, hace posible ampliar y precisar los resultados en varios aspectos, como el distinto $t i$ ming con que los gobiernos estatales empezaron a fiscalizar las actividades exportadoras, la proporción de los ingresos estatales que tuvo ese origen, y los contrastes existentes entre estados o grupos de estados con características comunes.

Como se mostrará en este trabajo, la obtención de ingresos del sector exportador por la vía fiscal no era automática, y mientras algunas entidades diseñaron tempranamente mecanismos para extraer recursos de él, otras lo hicieron en forma tardía o no lo hicieron a lo largo de la era exportadora. Si bien este acercamiento general no permite vislumbrar las causas de la distinta responsividad de los erarios estatales ante esa nueva fuente de ingresos, sí ofrece un panorama general a partir del cual esa diversidad se hace evidente, facilitando estudios de caso o comparaciones al interior de grupos con características similares.

El tema de la fiscalización estatal de las exportaciones remite necesariamente al problema de las competencias fiscales, en particular entre la federación y los estados, y la forma en que aquellas se modificaron a lo largo del periodo. ${ }^{2}$ Los mayores cambios tuvieron lugar en relación con el sector minero, pues a partir de 1884 se inició un proceso de federalización (centralización) que pronto restringió la facultad de los estados para imponer gravámenes sobre él y que en esta primera etapa culminó en 1926 con la creación de las "participaciones" estatales en la recaudación federal. ${ }^{3}$ En el sector petrolero la primacía de la federación se impuso desde la primera ley sobre la materia, reservándose a estados y municipios una participación en la recaudación. El caso de las actividades agrícolas de exportación es distinto en varios aspectos. Por una parte, desde los años ochenta, los estados transferían una parte de los impuestos recaudados sobre ellas al gobierno federal. Por otra, en el marco de una gran diversidad de experiencias, estas fueron las que más padecieron el problema

${ }^{2}$ Este problema, presente desde el siglo XIX, no fue resuelto en la organización fiscal derivada de la Constitución de 1917, pues esta no ofreció una delimitación de los campos de imposición entre estados, municipios y la federación. Navarro, "Sistema", 1927, p. 12. En la Primera Convención Nacional Fiscal, realizada en 1925 con delegados de todos los estados, se trató el problema y se decidió enfrentarlo mediante una sistematización impositiva que empezó a ponerse en práctica en 1926. SHCP, Primera, 1926 (véase sobre todo la tercera sección).

${ }^{3}$ De acuerdo con Luis Jáuregui, a lo largo del siglo Xx "el Estado prefirió una baja carga fiscal a cambio de centralizar el mayor número de decisiones fiscales en el poder ejecutivo federal". Jáuregui, "Vino", 2003, p. 738. En el periodo que nos ocupa, el proceso de federalización estuvo lejos de ser lineal y se vio interrumpido en la década de 1910 por la guerra civil, cuando los gobiernos estatales y municipales aprovecharon la disrupción del orden federal para imponer contribuciones de distinto tipo. Tampoco fue completo, pues todavía en 1925 se definieron impuestos específicos que podían ser recaudados por los estados y de los cuales participarían los municipios. Kuntz, Exportaciones, 2010, p. 203. 
de la concurrencia fiscal, por lo menos en aquellos periodos en que la federación decidió imponer derechos de exportación a productos que ya soportaban gravámenes en el plano estatal y municipal. No obstante, la federalización propiamente dicha llegó mucho más tarde a las actividades agrícolas, por lo que los estados se beneficiaron de ellas dentro de un lapso temporal mucho mayor. En fin, el tema de los impuestos municipales es aún más complejo y sólo se abordará aquí de manera puntual para dilucidar aspectos relacionados con las haciendas de los estados.

En el caso de México, es más o menos conocido el peso de la derrama fiscal de las exportaciones sobre los ingresos públicos federales. ${ }^{4}$ En el plano estatal, varias investigaciones han destacando diversos aspectos del sistema hacendario, los cambios en la correlación de fuerzas entre la federación y los estados, o los problemas de la fragmentación y la desigualdad regional, aunque no necesariamente se han interesado por la contribución fiscal de las exportaciones. ${ }^{5}$ Mucha menor atención ha recibido el estudio de esta dimensión del problema para los erarios estatales considerados en su conjunto, entre otras cosas por las dificultades no menores que representa su análisis. Una de ellas tiene que ver con el carácter fragmentario de las fuentes existentes y con la inmensidad de la tarea de reunir información acerca del sistema hacendario y sobre las cuentas propiamente dichas de las finanzas estatales, para todos los estados del país y para al menos algunos años representativos dentro de las cinco décadas que abarca este periodo. Otra dificultad se relaciona con el propio análisis de la fiscalidad estatal y con el hecho de que no siempre es posible aislar aquellos impuestos que en sentido estricto se originaban en actividades exportadoras. Esta limitación es en algunos casos insalvable, pues si bien muchos gravámenes se imponían expresamente sobre la producción de bienes exportables, muchos otros eran gravámenes generales sobre la propiedad o el consumo, sin que sea posible calcular con precisión la medida en que la recaudación representaba una derrama directa de las actividades relacionadas con la exportación.

${ }^{4}$ Kuntz, Exportaciones, 2010, cuadro 1.3.

${ }^{5}$ Servín, Finanzas, 1956; Aboites, Excepciones, 2003, y Díaz, Political, 1997. Para un trabajo que sí se enfoca en el papel del auge exportador sobre las finanzas estatales véase Zuleta, Cultivos, 2006. Otro trabajo reciente, a cargo de Dobado y Silva, explora comparativamente la contribución de las exportaciones mineras en México y España en el periodo anterior a la primera guerra mundial. En el caso de México, los autores no se adentran en la contribución a las finanzas estatales debido a las carencias documentales: "Por desgracia, no existen menciones a la relación entre impuestos mineros estatales e ingreso total ni siquiera en fuentes secundarias." Dobado y Silva, "Crecimiento", 2007, p. 496. 
Debido a la ausencia de información completa sobre el tema, en este trabajo echaremos mano de un procedimiento con dos grados distintos de aproximación. Por un lado, se comparan los ingresos públicos ordinarios de los estados en algunos momentos representativos del ciclo exportador a fin de contrastar entre estados exportadores y no exportadores y por esa vía estimar la significación de las exportaciones en la prosperidad de las finanzas estatales. Por el otro, se contrastan los ingresos originados en actividades exportadoras en los diferentes estados, con el propósito de estimar la contribución directa de las exportaciones al erario de cada uno de ellos. ${ }^{6}$ Con el propósito de evitar una posible confusión de términos, conviene aclarar que cuando se menciona la derrama (o contribución) fiscal directa de las exportaciones, se alude a todos los ingresos estrictamente derivados de las actividades exportadoras, ya sea que estos provengan de la producción o de las ventas. La derrama fiscal indirecta alude, entonces, a la que se origina en actividades productivas y comerciales pertenecientes al sector interno en la medida en que han sido dinamizadas por las exportaciones. No debe confundirse este uso con el que distingue convencionalmente las distintas formas de tributación: directa (impuestos sobre la propiedad, la producción o los ingresos) e indirecta (impuestos sobre las transacciones y el consumo).

$\mathrm{Al}$ realizar este ejercicio tenemos conciencia de que el comportamiento de los ingresos, aunque en alguna medida puede reflejar el desempeño del sector exportador y los ciclos de la economía internacional, no es un resultado automático de alguna de esas variables, y ni siquiera traduce en forma directa y uniforme la aparición y el despliegue de las actividades exportadoras. Expresa también, en medida importante, la estructura fiscal de cada entidad y la capacidad -diferente de un estado al otro y a lo largo del tiempo- de los gobiernos estatales para gravar las actividades productivas, resultante de la negociación permanente con el gobierno federal y con las empresas dedicadas a producir para la exportación. A su vez, estas variables se vieron afectadas por la guerra civil y sus consecuencias de mediano plazo sobre la administración y la organización hacendaria. Pese a la incidencia de estos y otros factores y los cambios que se produjeron a lo largo del periodo, la evidencia sugiere que, en términos generales, existió una asociación positiva entre la presencia de actividades exportadoras exitosas y la prosperidad en las finanzas públicas, de manera que, incluso si aquellas no eran directamente gravadas, su auge se traducía en la bonanza de los estados que les servían de asiento.

${ }^{6}$ Cabe mencionar que al abordar el tema, este trabajo se enfoca en los ingresos públicos de los estados sin reparar en la dimensión del gasto, es decir, del uso más o menos productivo que se hizo de esos recursos. 
Este trabajo ofrece un acercamiento inicial y panorámico al problema de la contribución de las exportaciones a las finanzas públicas de los estados durante la primera era de las exportaciones (1880-1929). En el primer apartado se hacen algunas anotaciones sobre la metodología, la cobertura y las fuentes, a fin de delimitar más claramente los alcances de este ejercicio. En el segundo se ofrece una aproximación comparativa a los ingresos públicos de los estados de la república en distintos momentos del auge exportador. En el tercero se aborda la misma muestra de estados desde el punto de vista de los impuestos originados en las actividades exportadoras. El trabajo cierra con algunas conclusiones provisionales.

\section{NOTAS SOBRE METODOLOGÍA, COBERTURA Y FUENTES}

El ejercicio que proponemos en este trabajo es esencialmente comparativo, lo cual posee diversas limitaciones e impone otras tantas exigencias que es necesario explicitar. Por una parte, no está de más insistir en la fragilidad de las cifras disponibles. Aunque toda la información acerca de las finanzas estatales procede de fuentes oficiales, con gran sorpresa constatamos que discrepa, a veces ampliamente, de la utilizada en otra investigación que se sustenta también en una fuente oficial de la época, y que fue ella misma producida por una agencia gubernamental. ${ }^{7}$ Por otra parte, se han utilizado cifras de población por estado (a fin de calcular ingresos públicos per cápita) que, como se sabe, son de confiabilidad variable. ${ }^{8}$ Otra limitación tiene que ver con la cobertura de la información por estados; esta es incompleta para Guanajuato y Oaxaca, por lo que no siempre aparecen en las estimaciones. Además, se han excluido algunos estados que tuvieron esa categoría sólo durante una parte del periodo, pues no aparecen en las estadísticas de ingresos estatales de la época porfiriana. Se trata de Quintana Roo y Nayarit, así como el territorio de Baja California. ${ }^{9}$ Pese a la segregación que padeció en 1902 al separársele Quintana Roo,

${ }^{7}$ Servín, Finanzas, 1956. He preferido atenerme a las fuentes originales por varias razones. Una es que el autor sólo se ocupa de los años posteriores a 1900, mientras que aquellas permiten incluir un año previo al inicio de la era exportadora propiamente dicha. Otra es que aquellas cifras coinciden en mayor medida -cuando ha sido posible cotejarlas- con las que proporcionan las memorias de los estados u otras fuentes directas. En forma complementaria se utiliza este tipo de documentos para confirmar, precisar o corregir la información obtenida en las fuentes generales.

${ }^{8}$ Cuando no se dispone de este dato para los años que se utilizan como referencia se utiliza el promedio de los años más cercanos disponibles.

${ }^{9}$ El territorio de Quintana Roo se creó en 1902, y el de Tepic se convirtió en el estado de Nayarit en 1917. En cuanto al territorio de Baja California, en las estadísticas de los años veinte aparecía ya dividido en sus distritos Norte y Sur, y estos se convirtieron en territorios separados en 1931. Como se sabe, los territorios dependían directamente de la federación. O’Gorman, Breve, 1937. 
sí se incluye el estado de Yucatán, una entidad exportadora por excelencia, advirtiendo desde ahora acerca del posible -aunque tenue- efecto de aquella división sobre la evolución de sus finanzas.

Otra índole de aclaraciones tiene que ver con el análisis propiamente dicho. A fin de valorar el papel de las exportaciones en el desempeño de las finanzas estatales, se hace necesario distinguir entre estados exportadores y aquellos que no lo eran, e incluso, para mayor ahondamiento, diferenciar dentro de los exportadores entre sus distintas especializaciones productivas (mineros, agroganaderos, petroleros, o dos de las anteriores). Para llegar a esta clasificación se han empleado fuentes estadísticas y estudios cualitativos acerca de la actividad económica de cada estado y región. ${ }^{10}$ El resultado que se presenta aquí es preliminar y está abierto a modificaciones posteriores.

Pese a su importancia para los propósitos del análisis, es evidente que esta tipología no puede ser llevada al extremo, pues seguramente todos los estados de la república realizaron en algún momento alguna exportación. En este sentido, la primera distinción realizada apunta a identificar los estados en los que las exportaciones poseían una significación destacada, representando en muchos casos la actividad predominante en el marco de la economía mercantil (como en Yucatán y Campeche). Ciertamente, hubo estados con una compleja diversificación productiva (como Jalisco y Nuevo León), en los que la actividad exportadora coexistía con un importante sector orientado al mercado interno. Estos casos se incluyen también entre los exportadores, por cuanto en ellos las ventas externas aparecieron en un lugar prominente en los recuentos de la vida económica estatal en al menos una parte del periodo considerado. En suma, los estados que quedan al margen de esta definición son aquellos en los que no existió una especialización exportadora significativa y consistente, es decir, que no hubo exportaciones mineras en volúmenes considerables ni algún producto agrícola, forestal o pecuario destinado a la exportación que destacara en su espectro productivo en algún momento del periodo.

Entre los estados que forman este pequeño grupo de entidades no exportadoras se encuentran varios de los principales productores de granos y otros artículos de la agricultura comercial para el mercado interno

\footnotetext{
${ }^{10}$ Se identificó como exportadores mineros a aquellos que producían cantidades de minerales y mantenían un número de minas y de operarios activos por encima de un límite inferior fijado por la autora de estas líneas. Como se verá en su momento, no todos los estados mantuvieron su importancia en este terreno a lo largo de todo el periodo. Entre las fuentes empleadas para elaborar esta clasificación se encuentran en El Colegio de México, Estadísticas, 1960 [1961?]; Romero y Cortés, Comité, 2007, y DEN, Algunos, 1929. Para identificar a los estados especializados en exportaciones agropecuarias se recurrió a Kuntz, Exportaciones, 2010, donde se ofrece un análisis por productos que incluye su emplazamiento geográfico en el territorio nacional. No se consideraron aquellos productos de exportación que poseían una presencia estadística insignificante.
} 
(Querétaro, Puebla) así como otros que se concentraron en satisfacer una demanda regional (Colima, Tlaxcala). Se incluyen también los estados de Morelos y Guerrero, cuya presencia en este grupo (de estados no exportadores) requiere una mayor explicación. En primer lugar, llamará la atención que se ubique en esta categoría al estado de Morelos, principal productor de azúcar del país durante el porfiriato. La idea de que Morelos era un estado exportador de azúcar, y en general de que el azúcar era un artículo de exportación en la economía mexicana de esa época, es básicamente errónea. Como se ha mostrado en otras partes, el azúcar fue primordialmente un producto destinado al mercado interno. ${ }^{11}$ Lo que es más, este producto fue de hecho objeto de una amplia protección estatal frente a las importaciones, y hasta 1910 sólo esporádicamente se exportó el excedente. ${ }^{12}$ Fue únicamente a partir de la década de 1920 que el azúcar empezó a figurar de manera consistente entre las exportaciones agropecuarias, pero para entonces Morelos había dejado de ser un productor dominante a escala nacional. Algo similar sucede con el estado de Guerrero, al que suponemos frecuentemente como un importante exportador de plata. Sin ser falso, este supuesto constituye una fuerte exageración. Guerrero producía plata y probablemente exportaba una pequeña parte de ella (pues el resto se empleaba en la orfebrería tradicional de la región), pero la ley de los minerales a fines del siglo XIX solía ser baja y los costos de transporte elevados, por lo que su papel como exportador no era significativo. ${ }^{13}$ Cuando los métodos de procesamiento permitieron un resurgimiento de la minería guerrerense en el segundo lustro de los años veinte, el valor de la producción del estado seguía siendo modesto, ocupando en 1927 el lugar trece entre los estados productores de plata del país. ${ }^{14}$ Así pues, el grupo de entidades clasificadas para propósitos del análisis como no exportadoras quedó conformado por Colima, Guerrero, Morelos, Puebla, Querétaro y Tlaxcala.

Una vez agrupados en estados exportadores y no exportadores, se crearon subgrupos entre los estados exportadores para distinguir tres clases principales: los estados en los que la especialización minera era ampliamente predominante; aquellos en los que destacaba con claridad una espe-

\footnotetext{
${ }^{11}$ Crespo, Historia, 1988, pp. 278-285; Riguzzi, "Mercados", 1999, pp. 50 y ss., y Kuntz, Exportaciones, 2010, cap. 7.

${ }^{12}$ En este concepto debe ubicarse el breve auge de las exportaciones de azúcar que tuvo lugar en algunos años de la primera década de 1900. Véase Crespo, "Nuevo", 2011, p. 391.

${ }^{13} \mathrm{La}$ escala misma de la producción era pequeña en la última década del siglo XIX, como lo sugiere el número de trabajadores empleados (1 450 en promedio, frente a 8000 de Durango, para sólo mencionar un ejemplo de estado netamente minero) y el número de máquinas de vapor en uso (un máximo de catorce en esa década, frente a 40 de Oaxaca o 92 de Chihuahua). El Colegio de México, Estadísticas, 1960 [1961?], pp. 130-131.

${ }^{14}$ DEN, Algunos, 1929, p. 24.
} 
cialización agropecuaria (incluida la rama forestal), y un tercer subgrupo de estados que desarrollaron ambos perfiles, de manera que exportaban productos mineros y agroganaderos a la vez. El inicio de la producción de petróleo para la exportación en la década de 1910 nos llevó a crear un cuarto subgrupo para incluir estados cuya especialización sufrió algún cambio importante a lo largo del periodo. Es el caso de estados exportadores de productos agropecuarios que a partir de 1911 lo fueron también -y en forma prominente- de petróleo (Veracruz y Tamaulipas), así como de estados en los que el auge de las exportaciones tuvo una vigencia temporal limitada: Aguascalientes (cuya producción metalúrgica arrancó en los años de 1890 y prácticamente desapareció en los años veinte con el traslado de la planta a San Luis Potosí) y Oaxaca (cuya producción minera decayó por completo al finalizar el porfiriato) (véase esquema 1).

Esta tipología, que no es ni rígida ni definitiva, nos permitirá simplificar el análisis que se realiza en el siguiente apartado.

Por último, cabe decir algunas palabras acerca de la disponibilidad de información y de la cobertura temporal del análisis. Como se mencionó antes, la perspectiva adoptada en este trabajo nos ha hecho preferir fuentes homogéneas que agrupen datos para todos los estados de la federación, frente a la alternativa de agrupar datos fragmentarios y dispersos, estado por estado, para construir un cuadro que sería necesariamente incompleto y tendría además la desventaja de una fuerte heterogeneidad en la información. No obstante, cuando se ha dispuesto de información de primera mano que completa o contradice la provista por estas fuentes de carácter general, se ha incorporado aquella con el fin de reducir los sesgos que pueden resultar de las deficiencias en estas. Dentro de la opción elegida, se buscó conciliar la disponibilidad de fuentes con los requerimientos del análisis. Pese a que existen recuentos oficiales de las finanzas estatales para la década de 1880, para los años 1905-1910 y para algunos otros de la década de 1920, es insuficiente para llevar a cabo un ejercicio serial, por lo que hemos optado por tomar años de referencia, procurando que sean normales y lo suficientemente espaciados para reflejar los cambios que deseamos identificar. Asimismo, se deja de lado el análisis de las finanzas estatales durante la década de 1910, pese a que entonces llegaron a su apogeo algunos de los productos que México ofrecía en el mercado internacional, pues el caos político y administrativo generado por la guerra civil hizo que la recaudación fuera en sí misma irregular y que, en consecuencia, la reconstrucción de cifras fidedignas sea prácticamente imposible. ${ }^{15}$ Así

${ }^{15}$ De hecho, pese a que durante la lucha armada los distintos ejércitos impusieron contribuciones extraordinarias a muchas actividades económicas orientadas a la exportación, esta derrama fiscal generalmente se dilapidó en el sostenimiento de la guerra civil; sólo en algunos estados, y 


\section{ESQUEMA 1. CLASIFICACIÓN DE LOS ESTADOS SEGÚN SU ESPECIALIZACIÓN EXPORTADORA}

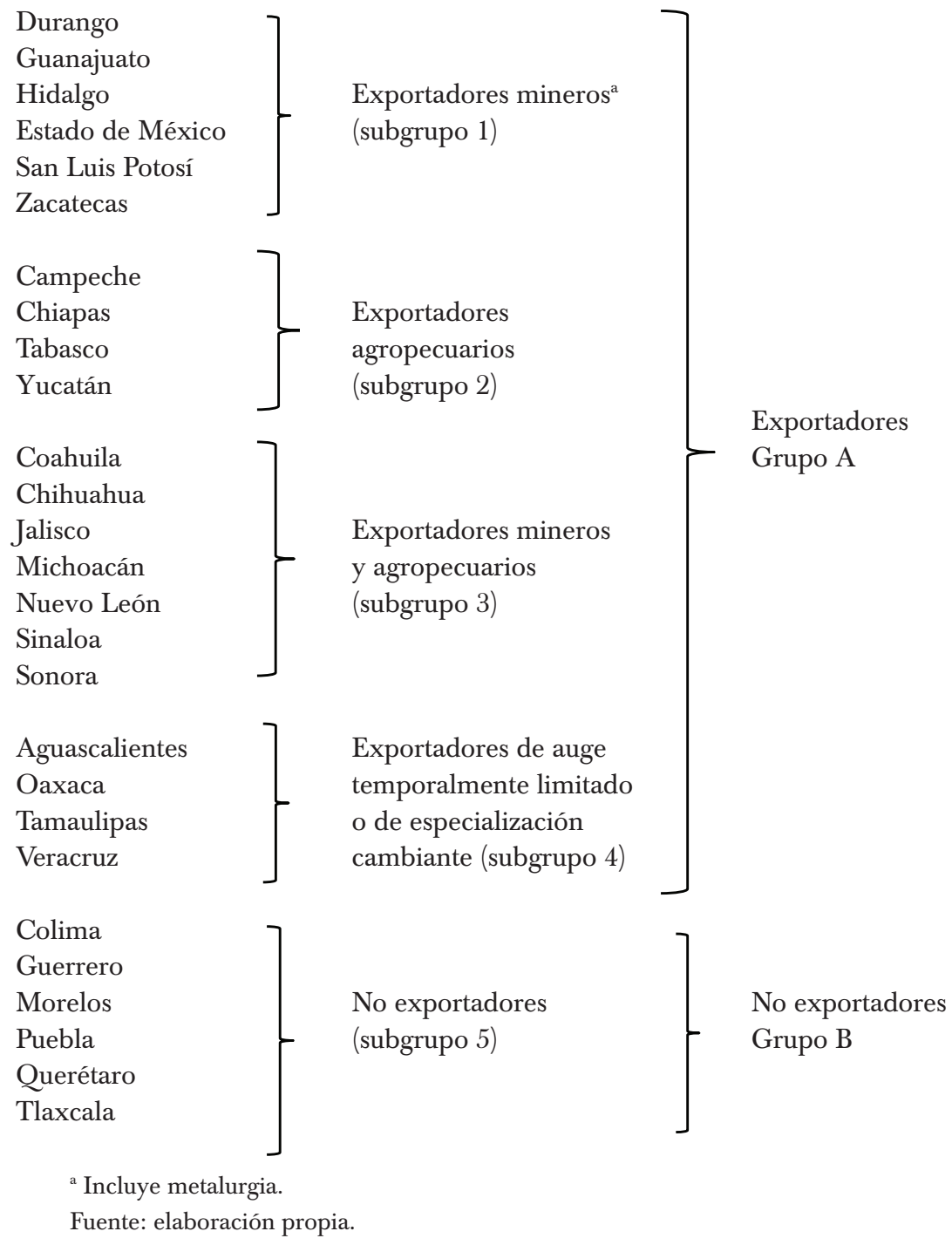


las cosas, se ha procurado incluir indicadores que correspondan a un momento temprano, previo al despegue de las exportaciones (el año fiscal de 1879-1880), al auge $(1890,1905)$ y a un año significativo de la fase final del ciclo exportador (1926), que al mismo tiempo exhibe el mayor despliegue de las exportaciones en términos del número de regiones y productos involucrados y anuncia el inicio de su declive en términos de valor.

Como no es el propósito de este ejercicio comparativo poner a prueba la confiabilidad de las fuentes disponibles, se ha partido del supuesto de que aquellas reflejan en forma aproximada la evolución de las finanzas estatales a lo largo del periodo. Se asume que pueden existir errores de registro en algún año, o que la información de algunos estados puede ser menos fiable que la de otros, pero se opta por colocar el acento en la valoración de conjunto. Aunque en términos generales se aprecia una consistencia aceptable en los datos y en el comportamiento esperado entre las variables estudiadas, las inconsistencias que se observan son destacadas y comentadas en su oportunidad.

\section{ANÁLISIS COMPARATIVO DE LOS INGRESOS ORDINARIOS DE LOS ERARIOS ESTATALES}

El primer indicador que utilizaremos para valorar la importancia de la derrama fiscal de las exportaciones sobre los estados es el de la evolución de los ingresos ordinarios totales. Se trata de un indicador general, que expresa apenas la posible relación entre éxito exportador y éxito hacendario. No obstante, tiene la ventaja de que permite incluir en la valoración no sólo la derrama directa y visible de las exportaciones, sino además tanto la derrama oculta de carácter directo como su derrama indirecta. Con "derrama oculta" me refiero a ingresos fiscales originados directamente en las exportaciones pero comprendidos en impuestos cuya denominación no permite adivinar ese origen o separarlos de los relacionados con actividades del mercado interno. Se trata, por ejemplo, de las contribuciones prediales (en particular sobre propiedades rústicas), sobre las ventas, o sobre operaciones de traslado de propiedad. En un estado exportador, se puede suponer sin gran riesgo que muchos de estos ingresos estuvieron asociados con actividades de exportación. Con "derrama indirecta” me re-

en otros de manera esporádica, esta derrama benefició a las haciendas estatales. De ahí que nos parezca inapropiado estimar los datos faltantes de esa década "conforme a trayectorias propias del ingreso o egreso de la entidad considerada", como se hace en Servín, Finanzas, 1956, anexo 1. Ingresos. Para un acercamiento más sensible al tema desde el punto de vista federal, véase Uhthoff, Finanzas, 1998; sobre el caso específico de los derechos sobre el comercio exterior, Uhthoff, Impuestos, 2005. 
fiero, como se explicó ya, a la derivada de todas aquellas actividades que, sin formar parte del sector exportador, fueron dinamizadas por las exportaciones. Los ejemplos más notables son los impuestos sobre el comercio y sobre giros mercantiles e industriales (que pueden abarcar también cierta derrama directa pero oculta de las exportaciones). Esta derrama fiscal indirecta es relevante para nuestra valoración en la medida en que apunta también a posibles eslabonamientos de las actividades exportadoras con otras en el entorno regional. Para dar un ejemplo de esto, entre 1887 y 1901, en el marco del primer auge del henequén en Yucatán, los ingresos por la producción de fibra (derrama directa) aumentaron a una tasa media anual de $5 \%$, un ritmo de por sí excepcional en el contexto nacional, pero la derrama fiscal indirecta relacionada con el comercio de carnes y con la producción y ventas de aguardiente y licores creció aún más rápido, a una tasa promedio de $6 \%$ anual. ${ }^{16}$

Empecemos por comparar de manera gruesa el comportamiento fiscal de los estados exportadores respecto al de los no exportadores. La situación de los erarios estatales en el año inicial (1879-1880) no permite percibir algún patrón en términos de tamaño, dotación de recursos, especialización productiva u orientación de la producción. Los cinco estados con la recaudación per cápita más elevada (Morelos, Colima, Campeche, Zacatecas y Veracruz) eran diversos en todos estos aspectos; si acaso destaca la especialización azucarera de Morelos, la minera de Zacatecas y el carácter de principal puerto de Veracruz. Esta imagen se había transformado para 1926. Los cinco estados con mayores ingresos se caracterizaban entonces por ser exportadores de primer nivel, con Yucatán a la cabeza, seguido por Campeche, Sinaloa, Tamaulipas y Chihuahua. Por cierto, sólo uno de estos era un estado minero, mientras que tres eran grandes exportadores agrícolas y uno más, petrolero. Este ejemplo ya permite atisbar la estrecha relación entre éxito exportador y éxito fiscal, pero esta se pone en evidencia al agrupar la información (véase cuadro 1).

El cuadro ofrece dos indicadores de la evolución de los ingresos públicos de los estados, distinguiendo entre estados exportadores (grupo A) y no exportadores (grupo B), conforme a la agrupación propuesta en el esquema 1. El primero de estos indicadores es el valor real de los ingresos públicos per cápita en los cuatro años de referencia. Como era de esperarse, su promedio nacional se incrementó en forma considerable, al pasar

${ }^{16}$ Archivo General del Estado de Yucatán (en adelante AGEY), Congreso del Estado, Contaduría Mayor de Hacienda, caja 94, vol. 1, exp. 12, y caja 95, vol. 2, exp. 9. Cecilia Zuleta ha estudiado con profundidad el caso de la relación entre economía exportadora y hacienda estatal durante el porfiriato para Yucatán. Como explica la autora, una reforma hacendaria al interior del estado permitió explotar al máximo el auge de la fibra en el mercado mundial. Zuleta, Cultivos, 2006, pp. 256-285. Véase también Zuleta, "Hacienda", 2004. 


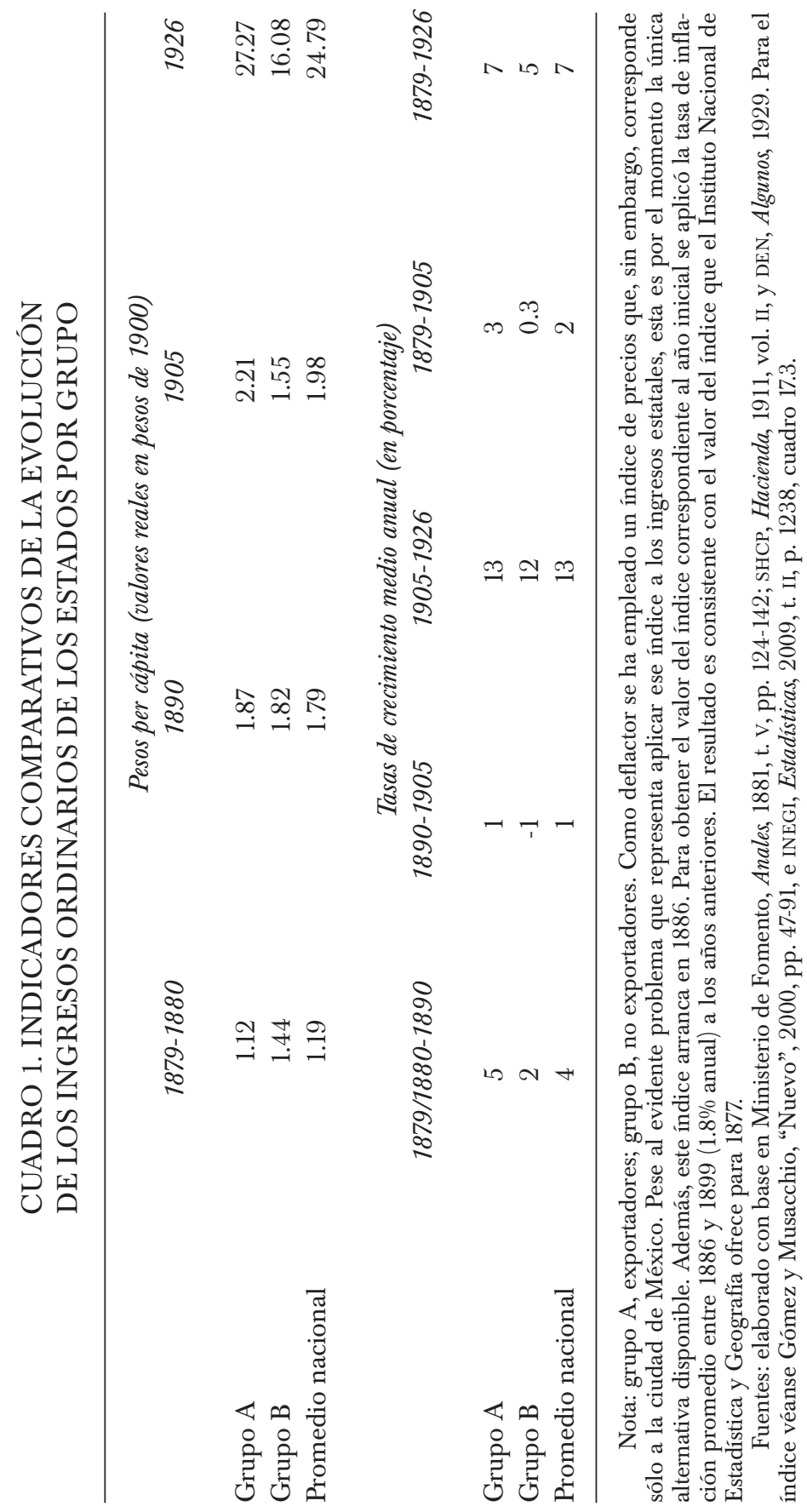


de 1.19 a 1.98 pesos por habitante de 1879-1880 a 1905 (un aumento de $66 \%$ ), y a casi 25 pesos per cápita en 1926. Menos esperado es el hecho de que en el año inicial los estados no exportadores exhibían ingresos per cápita 29\% superiores a los que se convertirían en exportadores -pero que, por lo general, todavía no lo eran. Esa ventaja desapareció en la primera década del crecimiento exportador, puesto que para 1890 la situación se había invertido, los estados exportadores ostentaban ingresos públicos per cápita ligeramente superiores (por el momento en apenas 3\%) a los de los no exportadores. Esta brecha se amplió con el curso del tiempo, para 1905 los erarios de entidades exportadoras percibían ingresos reales 30\% superiores, y esa ventaja llegó a 41\% en 1926. Estas cifras también destacan el aprendizaje de los estados exportadores en materia de obtener un beneficio fiscal significativo de su sector externo.

Un vistazo a las tasas medias de crecimiento de los ingresos públicos estatales en términos reales, incluidas en la segunda parte del cuadro 1, nos permite percibir mejor el timing de la divergencia entre ambos grupos. Asimismo, es interesante observar que hubo dos subperiodos en los que ese indicador experimentó un crecimiento acelerado: los años 1879/18801890 y 1905-1926. En forma un tanto sorprendente, la etapa intermedia, que registró el mayor auge de las exportaciones pero también de la incipiente industrialización, decreció (en el caso de los estados no exportadores) o exhibió un incremento modesto (en el de los exportadores). Aun así, resulta notable la tasa de crecimiento correspondiente al conjunto de estados para todo el periodo, de 7\% como promedio anual.

Aun cuando el grupo A registró una disminución en el ritmo de crecimiento de los ingresos fiscales entre 1890 y 1905, el hecho de que incluso en este lapso su desempeño fuera mejor que el del grupo B obliga a matizar la noción de vulnerabilidad externa atribuida a las economías exportadoras. En efecto, el grupo B registró tasas negativas entre 1879 y 1905 , lo cual dejó un saldo muy pobre para el promedio del periodo 1879-1905 (tan sólo 0.3\%, frente a 3\% para el grupo A). La carga fiscal aumentó considerablemente para ambos grupos entre 1905 y 1926, pero aun entonces creció más rápidamente la que toleraban las actividades de exportación.

Para ahondar un poco más en este análisis consideraremos los subgrupos que se definieron en el esquema 1, en los que se identifica con mayor precisión la especialización productiva de las entidades exportadoras -y se mantiene, como subgrupo 5, la consideración de las no exportadoras. El cuadro 2 presenta los ingresos ordinarios (reales) per cápita en los cuatro años de referencia para cada uno de estos subgrupos.

Cabe hacer notar, en primer lugar, que en el año inicial los subgrupos uno al cuatro (correspondientes a estados que eran o se volverían exportadores) registraban, cada uno, ingresos públicos por habitante inferiores 


\section{CUADRO 2. INGRESOS PÚBLICOS (ORDINARIOS) PER CÁPITA DE LOS ESTADOS POR GRUPO}

\begin{tabular}{lcccc}
\hline & $1879-1880$ & 1890 & 1905 & 1926 \\
Subgrupo 1 & 1.29 & 1.75 & 1.68 & 21.05 \\
Subgrupo 2 & 1.33 & 2.23 & 4.34 & 46.14 \\
Subgrupo 3 & 0.81 & 2.01 & 1.84 & 25.53 \\
Subgrupo 4 & 1.19 & 1.29 & 1.30 & 20.79 \\
Subgrupo 5 & 1.44 & 1.82 & 1.55 & 16.08 \\
Promedio nacional & 1.19 & 1.79 & 1.98 & 24.79 \\
\hline
\end{tabular}

Nota: para la composición de los subgrupos, véase el esquema 1. Para el índice de precios, véase el cuadro 1. (Pesos por habitante, valores reales en pesos de 1900).

Fuentes: elaboración propia con base en Ministerio de Fomento, Anales, 1881, t. V, pp. 124142; SHCP, Hacienda, 1911, vol. II, y DEN, Algunos, 1929.

al subgrupo cinco. Esta situación empezó a revertirse desde 1890 para algunos subgrupos hasta que, en 1926, ninguno registraba ingresos públicos inferiores a los del subgrupo cinco. Sin embargo, también entre los subgrupos exportadores existían diferencias significativas que de hecho se ampliaron con el paso del tiempo.

El dato más llamativo es que los ingresos públicos que más crecieron a lo largo de todo el periodo fueron los del subgrupo dos, de los exportadores agropecuarios, y no el de los estados mineros. Los ingresos promedio de ese subgrupo, que ya eran considerablemente más altos que el conjunto en 1905, alcanzaron en 1926 casi el doble de los que percibía cualquier otro subgrupo. Varios factores pueden explicar esta situación. Uno de ellos es el hecho de que la minería soportaba una carga impositiva de origen federal y la metalurgia un gravamen municipal, de manera que los impuestos estatales representaban sólo una parte de su contribución fiscal. Pero además, es sabido que desde que los asuntos de minas se volvieron de competencia federal, el gobierno (federal) estableció límites precisos a los gravámenes que los estados podían imponer a esta actividad productiva. En 1884 ese límite se estableció en 2\% del valor bruto de los metales extraídos (aunque esta disposición sólo se hizo vigente a partir de 1887), y en 1905 el tope se redujo a 1.5\% ${ }^{17}$ En 1919 se volvió al tope inicial (2\%) que se mantuvo en las leyes posteriores $(1924,1926,1929)$ sólo para el oro

${ }^{17}$ Velasco et al., Estado, 1988, p. 333. El carbón, el hierro y el petróleo estaban exentos de esta contribución. De ese porcentaje, los estados debían transferir 25\% por concepto de contribución federal. 
y la plata, mientras que para los otros metales se limitó a 50\% del monto impuesto a escala federal según una tarifa incluida en la propia ley. Un vistazo a esa tarifa denota claramente el propósito de favorecer la explotación de minerales no preciosos mediante la imposición de tasas módicas a su producción y de sistematizar la política (iniciada durante el porfiriato) de fomentar el procesamiento doméstico de los productos mineros. Ello redundó en impuestos módicos que disminuían a medida que aumentaba el grado de elaboración de los metales. Así, por ejemplo, el plomo estaba sujeto a la siguiente gradación impositiva: en mineral natural, 2\%; en concentrados, $1.8 \%$, en barras impuras, $1.5 \%$, y afinado, $1 \%{ }^{18}$ Como se explicó, los estados productores percibían solamente $50 \%$ de esas tasas, una disminución considerable respecto a los topes porfirianos. Finalmente, a partir de 1926 los impuestos estatales a la minería dejaron su lugar a las "participaciones estatales" en los impuestos federales. Como explica correctamente Luis Aboites, su aparición "refleja el esfuerzo federal por acabar con la concurrencia sobre las mismas fuentes tributarias", si bien ello no modificó las tasas impuestas. ${ }^{19}$ Aun cuando esta restricción dictada desde la esfera federal a todos los estados redujo el beneficio fiscal de las actividades mineras en el plano estatal, ello no obstó, como veremos más adelante, para que los ingresos por ese concepto representaran una contribución significativa para muchos erarios estatales.

Para referir otro factor que puede explicar el mejor desempeño de los ingresos de estados especializados en exportaciones agropecuarias respecto a los mineros, resulta pertinente recordar el argumento que esgrimía el estructuralismo para cuestionar las bondades del eslabonamiento fiscal; es probable que las actividades que producían menos encadenamientos industriales tuvieran como contraparte un mayor enlace fiscal. ${ }^{20}$ Acaso estas mismas razones sirven para explicar el mejor desempeño del subgrupo tres, de estados que eran a la vez exportadores agrícolas y mineros, respecto al subgrupo uno, de estados mineros; en general, tal parece que las

\footnotetext{
${ }^{18}$ Secretaría de Hacienda y Crédito Público, "Ley de impuestos a la minería (expedida el 8 de marzo de 1924)", Diario Oficial, 17 de marzo de 1924, pp. 963-966. La ley se reformó en algunos artículos en 1925.

${ }^{19}$ Secretaría de Hacienda y Crédito Público, "Ley de impuestos a la minería (expedida el 28 de julio de 1926)", Diario Oficial, 2 de agosto de 1926, pp. 1-8, y Aboites, Excepciones, 2003, p. 75. Por lo demás, el propósito de reducir la concurrencia fiscal alcanzó también a los productos forestales, los cuales a partir de 1927 fueron sujetos a un impuesto federal ("sobre explotación de maderas y bosques") del cual correspondería $15 \%$ a los estados y $15 \%$ a los municipios. Yáñez, Problema, 1958, t. III, p. 178. Sobre el problema de la concurrencia fiscal y la doble o triple imposición y otros problemas del sistema fiscal mexicano de estos años véase también Díaz, Political, 1997, pp. 52-56 y apéndice 1, pp. 348-352.

${ }^{20}$ Hirschman, "Desarrollo", 1984, pp. 91-95. Aunque debe insistirse en que, incluso teniendo un enlace fiscal, algunos productos agrícolas sí poseían eslabonamientos industriales.
} 
actividades agrícolas reportaban un beneficio fiscal mayor que el resto del sector exportador.

Volvamos al cuadro 2. Muy cerca de los estados especializados en exportaciones minero-metalúrgicas se encuentran los del subgrupo cuatro: estados cuya experiencia exportadora fue desigual o cuya especialización varió a lo largo del tiempo. El desempeño de los ingresos estatales de este subgrupo dejó mucho que desear, aunque se encontró aún por encima del de los estados no exportadores. Vale la pena ahondar en este comportamiento peculiar para cada uno de los estados. En el caso de Oaxaca, la falta de información para la mayor parte del periodo (sólo dispongo del dato para el año inicial y para el final) impide detectar el origen del problema, sólo sabemos que los ingresos crecieron poco en el largo plazo, pero no sabemos si se trató de un comportamiento constante o con altibajos. El caso de Aguascalientes es mucho más transparente: sus ingresos públicos fueron bajos y su crecimiento lento hasta 1890 , y se aceleró a partir de entonces. La razón consiste en el establecimiento de una planta metalúrgica que, si bien pagaba impuestos al municipio y no al estado, actuó como un factor fundamental para dinamizar el crecimiento urbano, los servicios y el comercio. El resultado fue una derrama fiscal indirecta que favoreció al erario estatal hasta que dicha planta fue cerrada en los años veinte. El contraste al interior de un mismo estado entre la situación fiscal con y sin actividades exportadoras constituye una prueba elocuente de la importancia de estas para la economía, en este caso en el plano estatal.

Los casos de Veracruz y Tamaulipas son más fáciles de dilucidar. El primero era una entidad de gran riqueza agrícola, cuyo erario obtenía ingresos elevados desde el primer año del periodo debido al gran dinamismo comercial del principal puerto del país. De esta manera, el auge exportador no representó un brinco desde la indigencia presupuestal hasta la prosperidad -como sí sucedió en otros casos. En cambio, el tránsito que se produjo en el último periodo, en virtud del cual a la especialización agraria se añadió la petrolera, sí representó un salto significativo en las finanzas estatales, duplicando la tasa de crecimiento que se había registrado hasta entonces. El segundo testifica el salto desde una economía regional agraria moderadamente exitosa en sus primeras fases y una ligada a un artículo en pleno auge exportador, el petróleo, incluso si ese auge ya se estaba eclipsando en 1926.

\section{CONTRIBUCIÓN FISCAL DIRECTA DE LAS EXPORTACIONES}

La información de que disponemos permite hacer un acercamiento a la estructura de los ingresos por estado en tres momentos del periodo de es- 
tudio, para lo cual se han elegido los años 1879-1880, 1905 y 1926, con los que se elaboró el cuadro 3. En él se presentan los ingresos que los estados obtuvieron por conceptos relacionados directamente con las exportaciones (incluidos en este caso tanto los estados exportadores como los no exportadores, según la clasificación del esquema 1). Por cuanto la información no es homogénea entre los años referidos, cabe explicar algunas especificidades y limitaciones que imponen las fuentes.

La primera de ellas tiene que ver con el tipo de datos que se incluye en el cuadro 3. Se trata de manera exclusiva de los impuestos cuya denominación permite inferir que se relacionan directamente con las exportaciones. No obstante, existe un margen de error (y un sesgo hacia arriba) en el caso de actividades que podían tener orientación hacia los mercados interno y externo. En este sentido, los datos correspondientes a 1905 son los más prolijos, pero al mismo tiempo los que se prestan en mayor medida a una mala interpretación. Para ejemplificar el problema y la solución que le hemos dado, mencionemos que algunos estados del norte imponían gravámenes sobre la ganadería. Como estas entidades eran grandes productoras de ganado y dedicaban buena parte de su crianza al mercado estadunidense, incluimos el valor total de los ingresos originados en ese gravamen, incluso si una parte de las ventas se destinó seguramente al mercado interior. ${ }^{21}$ En cambio, se dejan de lado esos mismos impuestos cuando sabemos que los estados que los reportaron no destinaban su producción al mercado externo. Es el caso, por ejemplo, de Hidalgo y Tlaxcala, cuya producción ganadera se orientaba en su mayoría a satisfacer la demanda regional.

En cambio, hay un sesgo aún más pronunciado hacia abajo debido a la imposibilidad para cuantificar la derrama producida mediante gravámenes cuyo vínculo con las exportaciones no es posible discernir, como los que se imponían a los giros mercantiles e industriales o incluso sobre las fincas rústicas. En muchos de estos casos es probable que la adquisición de fincas o el establecimiento de un "giro industrial" tuviera una relación directa con el sector exportador: fincas destinadas al cultivo de artículos de exportación, o plantas de procesamiento de esos mismos artículos. La imposibilidad de reconocer en qué medida estos ingresos se originaron en las actividades exportadoras evidentemente impone una subestimación de la derrama fiscal directa de las exportaciones que aquí se pretende estimar. Aun cuando esta derrama oculta de las exportaciones estuvo seguramente presente en alguna medida en todos los estados de la república, en el cuadro sólo aparece consignada - pero no cuantificada- en los casos en que se tiene constancia de la existencia de impuestos que afectaban, entre otras

${ }^{21}$ En estos casos se señala esta posibilidad en la nota a pie del cuadro 3. 


\section{CUADRO 3. INGRESOS PÚBLICOS DERIVADOS DE IMPUESTOS A ACTIVIDADES EXPORTADORAS, AÑOS SELECCIONADOS (PORCENTAJE SOBRE EL TOTAL)}

1879-1880

1905

1926

Aguascalientes $^{\mathrm{a}}$

Campeche

Coahuila $^{\mathrm{a}}$

Colima

Chiapas

Chihuahua

Durango

Guanajuato

Guerrero

Hidalgo $^{a}$

Jalisco

México $^{\mathrm{a}}$

Michoacán

Morelos

Nuevo León

Oaxaca $^{\mathrm{a}}$

Puebla

Querétaro

San Luis Potosí

Sinaloa $^{\mathrm{a}}$

Sonora

Tabasco

Tamaulipas

Tlaxcala

Veracruz

Yucatán

Zacatecas

\begin{tabular}{|c|c|c|}
\hline & \multirow{3}{*}{$\begin{array}{c}9.4 \\
\underline{10.5}^{\mathrm{b}}\end{array}$} & 0.4 \\
\hline & & $\underline{29.0}$ \\
\hline & & $\underline{10.6}$ \\
\hline \multirow{3}{*}{3.3} & $\mathrm{DNC}$ & 8 \\
\hline & $21.5^{\mathrm{b}}$ & $\underline{20}$ \\
\hline & 14.9 & $\overline{6} .5$ \\
\hline 16.5 & 1 & 2.4 \\
\hline \multirow[t]{12}{*}{$\overline{0.2}$} & & 3 \\
\hline & $\underline{18}$ & $\underline{41}$ \\
\hline & DNC & 2 \\
\hline & 7.5 & 9 \\
\hline & 3.1 & 5.4 \\
\hline & ${\underline{38.3^{c}}}^{\mathrm{c}}$ & 1 \\
\hline & 2.3 & 2 \\
\hline & n. d. & 0.6 \\
\hline & & 3.6 \\
\hline & & 1.5 \\
\hline & 8.3 & 3 \\
\hline & $\underline{17.2}$ & 2.4 \\
\hline$\underline{19}$ & $\underline{25}$ & $\underline{12.4}$ \\
\hline \multirow[t]{2}{*}{5.8} & DNC & 9 \\
\hline & $\mathrm{DNC}$ & DNC \\
\hline \multirow[t]{3}{*}{8.6} & 2 & $\underline{6+16^{\mathrm{d}}}$ \\
\hline & $\underline{7+54^{e}}$ & $\underline{34}$ \\
\hline & $\underline{12}$ & DNC \\
\hline
\end{tabular}

Nota: se destacan con cursivas las cifras superiores a 5\%, y con cursivas y subrayado, las superiores a $10 \%$.

DNC, derrama no cuantificable.

n. d., no disponible.

${ }^{a}$ No es posible determinar con precisión el tipo de impuestos vigente para los años 1879-1880.

${ }^{\mathrm{b}}$ Incluye impuestos sobre ganado, en parte orientado al mercado interno.

${ }^{\mathrm{c}}$ Incluye impuestos al azúcar, que en parte se destinó al mercado interno.

${ }^{\mathrm{d}} 6 \%$ reportado en la fuente general más $16 \%$ de ingreso petrolero que reporta una fuente específica para 1922 (véanse fuentes abajo).

${ }^{\text {e }} 7 \%$ de ingresos ordinarios y $54 \%$ de una contribución extraordinaria sobre el henequén que estuvo vigente entre 1902 y 1906.

Fuentes: elaboración propia con base en Ministerio de Fomento, Anales, 1881, t. v, pp. 124142; SHCP, Hacienda, 1911, vol. II; DEN, Algunos, 1929, y Peña, Veracruz, 1946, p. 484. 
cosas, a las exportaciones, derivando en una derrama oculta e incuantificable. Por lo demás, este cuadro no considera la derrama fiscal indirecta que las exportaciones seguramente arrojaron al dinamizar otras actividades económicas en el plano estatal, y que se reflejó, por ejemplo, en impuestos al comercio, al registro de contratos, entre otros.

Un caso de comportamiento aparentemente anómalo que merece destacarse es el de Morelos. Aunque esta entidad ha sido excluida del grupo de estados exportadores, en el cuadro 3 se observa que en 1905 los ingresos acreditados a actividades relacionadas con la exportación son considerables. Se trata de una situación excepcional que se explica con detalle en otra parte, y que tiene que ver con un breve auge de las exportaciones del endulzante mexicano debido a "la confluencia de una sobreoferta en México con una crisis en la producción europea de remolacha que aumentó la demanda inglesa para el azúcar mexicana". ${ }^{22}$ Las exportaciones aumentaron de 8000 a 43000 toneladas entre 1902 y 1905, pero cayeron a tan sólo 5000 toneladas el año siguiente. Como muestra Cecilia Zuleta, los ingresos originados en la producción azucarera fueron muy importantes para el erario estatal, pero solamente en ese breve lapso tuvieron que ver con las exportaciones. Aun entonces, una parte significativa de la producción se destinó al abasto del mercado interno. ${ }^{23}$

En cuanto a los datos empleados para 1926, la fuente reporta dos tipos de impuestos que sugieren una relación con las actividades exportadoras: "impuestos sobre recursos naturales" e "impuestos sobre productos regionales". Como los primeros constituyen un paralelo exacto de los impuestos federales que llevaban el mismo nombre, sabemos sin lugar a dudas que afectaban a la minería y al petróleo. En cambio, los segundos no corresponden inequívocamente a productos de exportación. No obstante, la fuerte incidencia de esta fuente de ingresos en los estados exportadores (Campeche, Chiapas, Yucatán, etc.) y su insignificante o nula presencia en los que no poseían esa especialización (Colima, Morelos, Tlaxcala) dejan poco lugar a dudas sobre su origen. En cualquier caso, existe la posibilidad de que en este rubro participen, además de los artículos de exportación, otros orientados al mercado interno, lo cual entraña un pequeño margen de error (pequeño por la importancia relativamente menor de esta fuente de ingresos en estos casos en particular); con estas reservas véase el cuadro 3.

${ }^{22}$ Kuntz, Exportaciones, 2010, cap. 7.

${ }^{23}$ Zuleta, “¿Agridulces?”, 2011, p. 611. 
Lo primero que merece destacarse acerca del fenómeno que analizamos es que a medida que se desarrollaron las actividades exportadoras se desplegó también la capacidad de los gobiernos estatales para extraer beneficios fiscales de ellas -aunque la información disponible no nos permite identificar el timing con que tal asunto sucedió. En el umbral de la era exportadora (en el año fiscal 1879-1880), solamente de cinco estados puede asegurarse que imponían algún gravamen a actividades relacionadas con la exportación (Chihuahua, Guanajuato, Sonora, Tabasco y Veracruz), ${ }^{24}$ mientras que otros estados que ya eran netamente exportadores, como por ejemplo algunas entidades mineras, no lo hacían. ${ }^{25}$ Para 1905, 16 estados exportadores incluían en sus presupuestos gravámenes claramente relacionados con ese sector, y el número aumentó a 19 (de 21 clasificados como exportadores) para 1926. Inesperadamente, Tamaulipas y Zacatecas no reportaron en ese año ingreso alguno directamente relacionado con el sector exportador, lo cual, como veremos, se debe a una falla en la fuente de información.

Con las salvedades y limitaciones expuestas, el cuadro 3 permite valorar la importancia de los ingresos directamente originados en las exportaciones en el conjunto de haciendas estatales. Conviene recordar que los porcentajes contienen un sesgo hacia abajo cuando se trata de valorar la contribución fiscal total de las exportaciones en el plano estatal, puesto que se han excluido del cálculo los impuestos que gravaban indistintamente actividades orientadas al mercado interno y a la exportación, así como aquellos cuya relación con las exportaciones quedaba oculta en la denominación. ${ }^{26}$ Tampoco se consideran los beneficios fiscales que resultaban de la dinamización de otras actividades económicas, ya fueran productivas, comerciales y de servicios, generada por el sector exportador. Si adicionalmente se toma en cuenta que en muchos casos la estructura tributaria se encontraba considerablemente atomizada, se entenderá que los ingresos procedentes en forma directa de las exportaciones registren porcentajes en

${ }^{24}$ Para otros seis estados (señalados en el cuadro 3 con "a" en superíndice), la forma en que se presenta la información hace imposible reconocer claramente el origen de los ingresos. Es el caso, por ejemplo, cuando el desglose ofrece simplemente las asignaciones de cada uno de los municipios, o cuando, refiriéndose a los impuestos del estado, simplemente señala "contribuciones".

${ }^{25}$ Esto puede deberse a un error de la fuente, puesto que es muy improbable que las actividades mineras no estuvieran gravadas en el ámbito estatal. Sabemos, por ejemplo, que en el Estado de México existía, desde la primera mitad del siglo XIX, un impuesto sobre el oro y la plata extraídos del estado, que ascendía originalmente a 1.5 y en 1879 se elevó a $2 \%$ sobre el valor de los metales. Riguzzi, "Difícil”, 1994, t. I, p. 231.

${ }^{26}$ Como se mencionó antes, algunos impuestos pesaban igualmente sobre actividades orientadas al mercado interno y a la exportación, como los de fincas rústicas o el derecho de patente. Aunque no es posible discernir la proporción que correspondía a cada uno de esos destinos, se ha considerado importante señalar su existencia en el cuadro 3, para lo cual se emplean las siglas DNC. 
lo general modestos. En forma un tanto arbitraria y para los fines de este análisis comparativo, se considera que el enlace fiscal directo de las exportaciones posee una importancia baja cuando arroja porcentajes menores a $5 \%$ del total de los ingresos estatales en el año respectivo (y estos casos se presentan en el cuadro 3 con el tipo de letra normal). En segundo lugar, se estima de importancia media cuando aporta entre 5 y $10 \%$ del total (y se destacan con cursivas los casos correspondientes). Finalmente, se concede una importancia alta cuando la contribución directa de las exportaciones representa más de 10\% de los ingresos totales en el plano estatal (véase cuadro 3) (en cuyo caso se apuntan los datos con cursivas y subrayados).

Como el número de estados que reportó ingresos por exportaciones aumentó considerablemente, en 1926 incluso cuatro estados que hemos clasificado entre los no exportadores percibieron algún ingreso que pudo haberse originado en esa fuente, aunque su contribución fue muy pequeña. En los casos de Guerrero, Querétaro y Puebla, esa mínima aportación probablemente se derivó, en efecto, de actividades de exportación, pues en los dos primeros el rubro en el que se reportaron es el de "impuestos sobre la explotación de recursos naturales", y en el tercero este fue uno de los rubros mencionados. Los tres estados eran pequeños productores de minerales en ese momento: Guerrero sobre todo de plata; Puebla de zinc y cobre, y Querétaro de oro. Sin embargo, su aportación a la producción nacional era muy modesta (en 1927, ninguno aportó más de 1\% del valor total de la producción minera del país) y la importancia de la minería en la economía de esas entidades era también muy menor. ${ }^{27}$ En el caso de Puebla, una fuente mucho más importante que los recursos naturales para esos ingresos fue la de los llamados "productos regionales". Como se ha explicado antes, es imposible saber a qué productos se refiere esta denominación, aunque dada la especialización productiva de la entidad se podría sugerir que se trata sobre todo de tabaco y azúcar, los dos destinados al menos parcialmente al mercado interno. Finalmente, el otro estado no exportador que pudo haber tenido algún ingreso por concepto de exportaciones es Morelos, y el rubro por el que ingresaron esos recursos es el de "productos regionales". Es de suponer que se trata de azúcar, aunque el monto y la importancia relativa de esas percepciones (3 900 pesos, $0.8 \%$ de los ingresos del erario estatal) hace irrelevante toda especulación sobre el particular.

Por otra parte, el cuadro permite contabilizar el número de estados exportadores que, de acuerdo con las fuentes empleadas, no percibieron ingresos directamente originados en el sector exportador, o cuyos ingresos por ese concepto no pueden ser cuantificados (y aparecen entonces como

${ }^{27}$ DEN, Algunos, 1929. 
derrama no cuantificable-DNC). En el año inicial no es posible determinar ese número (véase nota 24); en 1905 sumó cinco y en 1926 disminuyó a dos. ${ }^{28}$ Para simplificar el análisis, podemos sumar a este grupo (de derrama fiscal nula o no cuantificable) todos aquellos estados exportadores que percibieron un beneficio fiscal bajo o moderado (menos de 10\%) en los tres años, o elevado (más de 10\%) pero en uno solo de los años referidos. Considerando los tres años de referencia, formaríamos así un grupo de doce estados en los que el impacto directo de las exportaciones sobre las finanzas estatales habría sido nulo (o no cuantificable), escaso o fluctuante en los años aquí considerados. A reserva de matizar en el futuro esta agrupación y las observaciones que siguen, se pude sugerir que ese resultado se explica por alguno de los siguientes factores: a) estados con economías muy diversificadas e importante desarrollo en actividades orientadas al mercado interno, ya fuera contrastante con una actividad exportadora relativamente modesta (Jalisco y Nuevo León), ${ }^{29}$ o complementaria de una actividad exportadora también significativa (Estado de México, San Luis Potosí y Veracruz); b) estados con actividades exportadoras no gravadas a escala estatal o de auge temporalmente restringido (Aguascalientes, Guanajuato), y c) estados que no imponían gravámenes específicos a las exportaciones (Chiapas y Tabasco); fallas derivadas de la información disponible (Sinaloa, Tamaulipas, Veracruz y Zacatecas), o una combinación de ambas.

Los casos agrupados en el inciso $a$ representan un grupo de estados -Jalisco, Nuevo León, Estado de México, San Luis Potosí y Veracruz- claramente identificable por el hecho de que en todos ellos existía una dotación de recursos abundante y variada y su actividad económica se encaminó, desde época temprana, por una senda de cierta diversificación productiva y comercial. Varios de ellos poseían recursos mineros, constituían centros regionales de intercambio y eran también el origen de circuitos interregionales más amplios, además de contar con una actividad manufacturera más o menos extendida. Los dos primeros desplegaban visiblemente una mayor actividad conectada al mercado interno y poseían sectores exportadores más modestos, lo cual se tradujo en una contribución proporcionalmente menor de las actividades exportadoras a sus finanzas públicas (menos de $3 \%$ en los años presentados aquí). Los tres mencionados en segundo

\footnotetext{
${ }^{28}$ Se excluye de esta consideración el estado de Oaxaca debido a la escasez de información disponible. En la primera década del siglo xx el gobierno del estado celebró igualas que sustituyeron al impuesto de 1.5\% sobre la explotación minera, lo que redituó entre 13000 y 16000 pesos por año al erario estatal. Existía, además, un impuesto sobre ventas aplicado a efectos que se vendían en otros estados o en el extranjero. No sabemos, sin embargo, lo que estos ingresos representaban como porcentaje de la recaudación total. SHCP, Hacienda, 1911, vol. II, pp. 238-239, y Chassen-López, Oaxaca, 2010, pp. 263-264.

${ }^{29}$ En este caso pueden ubicarse también los estados no exportadores que percibieron algún ingreso por sus modestas actividades de exportación, como Michoacán, Puebla y Querétaro.
} 
lugar ostentaban una actividad diversificada, pero también un sector exportador pujante y de gran tamaño, lo cual redundó en una contribución algo mayor. ${ }^{30}$ En estos casos, puede sugerirse que la regular contribución de las exportaciones es proporcional a la importancia del sector al interior de cada entidad, además de representar un suplemento en el marco del sistema tributario complejo.

Los casos del inciso $b$ refieren a Aguascalientes y Guanajuato, estados mineros con características diversas. Guanajuato, el gran polo de desarrollo de la minería colonial, imponía altísimos gravámenes a la producción de metales al inicio del periodo, antes de que los asuntos mineros se volvieran de competencia federal y se impusiera un tope a los impuestos estatales. Ello explica la contribución inusualmente alta (para un estado minero) que exhibieron las exportaciones de esta entidad en el año inicial $(16.5 \%)$. El tope establecido por la federación a partir de 1887 y la decadencia de la minería estatal explican el resto. La historia de Aguascalientes requiere una explicación más larga, que sólo en parte estamos en condiciones de presentar aquí. En los años iniciales del periodo, la minería se encontraba tan decaída que el gobierno de la entidad eximió la actividad de todo impuesto (disposición que estuvo vigente entre 1871 y 1883). La actividad minera siguió deprimida hasta mediados de la década de 1890, y entonces inició una era de mayor prosperidad que se prolongó hasta 1907 y que sin embargo debe atribuirse, más que a la modesta extracción local de minerales, al establecimiento de una importante fundición en la capital del estado, propiedad de la familia Guggenheim (ASARCO). La ausencia de ingresos fiscales en 1905 podría explicarse por las exenciones fiscales concedidas a los principales inversionistas, así como por el hecho de que eran los municipios, y no el estado, quienes imponían algunos gravámenes a la producción y al funcionamiento de la fundición. A principios de los años veinte, la negociación de los Guggenheim en Aguascalientes pagaba impuestos por alrededor de 1200000 pesos anuales al erario federal, lo que hace suponer beneficios proporcionales al erario municipal y una derrama indirecta para el estado, aunque no poseemos información que lo confirme. Para mediados de esa década la producción minera había decaído y, por esa y otras razones, la planta metalúrgica fue trasladada a otra entidad. ${ }^{31}$ De manera que en este caso serían los altibajos en la actividad (y acaso el nivel de la administración al que se imponían los gravámenes)

\footnotetext{
${ }^{30}$ De hecho, en el caso de San Luis Potosí, otras fuentes indican que tan sólo los impuestos originados en la actividad minera habrían aportado $11 \%$ de los ingresos estatales en 1905, lo cual significa que $8.3 \%$ reportado en la fuente empleada en el cuadro 3 constituye una subestimación. Gámez, "Prácticas", 2012, p. 157.

${ }^{31}$ Gómez, Aguascalientes, 1982, pp. 158 y 269-272.
} 
lo que explicaría la escasa contribución de las actividades exportadoras al erario estatal.

En cuanto a los casos comprendidos en el inciso $c$-Chiapas, Tabasco, Sinaloa, Tamaulipas, Veracruz y Zacatecas-, la explicación para el comportamiento observado parece encontrarse en uno de estos dos fenómenos: primero, el hecho de que las actividades de exportación fueran gravadas con los mismos impuestos que las orientadas al mercado interno (derrama oculta); segundo, que la fuente empleada aquí en forma preferente no registre la derrama fiscal de las exportaciones (fallas en la información). En el primer caso probablemente se encuentran los estados de Chiapas y Tabasco; en el segundo, los de Sinaloa, Tamaulipas, Veracruz y Zacatecas. En realidad, es probable que todos los estados que pertenecen a este inciso adolezcan de ambos problemas en alguna medida. Con todo, mantendremos aquí la distinción para los fines de la exposición.

Empecemos por los dos estados que se encuentran en el primer caso. En Chiapas el producto de exportación más prominente fue el café, y en una fase temprana su cultivo fue más bien incentivado mediante exenciones fiscales que gravado por la Hacienda estatal, con la excepción de la alcabala que se cobraba sobre la salida del café y que desapareció junto con ese derecho de tránsito. ${ }^{32}$ Además del grano se exportaban maderas finas y, a partir de cierto momento, caucho. En el primer decenio del siglo $\mathrm{XX}$ todas estas actividades eran gravadas mediante el impuesto de patente (que se aplicaba a los molinos de café, las negociaciones dedicadas al corte y explotación de maderas y las dedicadas a la exportación de gomas y resinas), el impuesto sobre fincas rústicas y el impuesto sobre ventas, entre otros. Los tres rubros mencionados aportaron en conjunto $40 \%$ de la recaudación estatal en 1905, pero es imposible discernir la parte de esos ingresos que correspondió a las actividades de exportación (respecto a las destinadas al mercado interior). ${ }^{33}$ De hecho, hasta la década de 1920 la derrama de las exportaciones era por esta razón incuantificable, y sólo en el último lustro del periodo se decretó un impuesto sobre la producción y otro sobre el beneficio del café.

El estado de Tabasco fue un exportador temprano de maderas preciosas y tintóreas y secundariamente de cacao. En 1879-1880 esas tres actividades dejaron un modesto beneficio al erario estatal, alcanzando casi $6 \%$ de sus ingresos ordinarios. Luego, la economía exportadora de la región se diversificó gracias a la explotación de caucho y de chicle. El que en 1905 no se registre ningún ingreso fiscal de esas fuentes no significa que estas actividades estuvieran exentas de todo gravamen, pues sabemos que

\footnotetext{
${ }^{32}$ Kuntz, Exportaciones, 2010, cap. 5.

${ }^{33}$ SHCP, Hacienda, 1911, vol. I, pp. 71-73, y vol. II, p. 409.
} 
pagaban el impuesto sobre fincas rústicas y el derecho de patente (que se imponía sobre los capitales empleados en la explotación de maderas preciosas y de tinte). Tanto en Chiapas como en Tabasco las exportaciones dejaron una derrama directa de entre 6 y $9 \%$ en dos de los años de referencia considerados, y muy probablemente beneficios ocultos durante gran parte del periodo. ${ }^{34}$

Los otros estados del inciso $c$-Sinaloa, Tamaulipas, Veracruz y Zacatecas- comparten la característica de que la información disponible acerca de los ingresos derivados de las exportaciones no es consistente con otros dos datos: primero, un desempeño exportador exitoso, y segundo, el hecho conocido de que sus actividades exportadoras poseían una derrama directa para el erario estatal. Veamos cada uno de estos casos por separado.

En Sinaloa, deficiencias en la fuente impiden estimar el origen de los ingresos públicos en el primer año considerado, aunque presumiblemente una parte de ellos se originaba en la actividad minera. La importancia de los ingresos por exportaciones en 1905 (17\% del total) es consistente con la significación de la minería estatal, y cuestiona la idea de que un tope impositivo de 1.5 o $2 \%$ implicara necesariamente un escaso beneficio fiscal. ${ }^{35}$ Lo que causa cierta perplejidad es la drástica caída en esa participación porcentual para 1926 (a 2.4\% del total), un momento en que, aun si la minería decaía, la actividad exportadora se expandía considerablemente. En esa fecha, Sinaloa era un gran exportador de jitomate, y empezaba a despuntar con ventas de garbanzo, melón y verduras al mercado exterior. Existe evidencia de que, a fines de la década, todos estos productos pagaban impuestos al erario estatal, y sin embargo estos ingresos no aparecen contabilizados en la fuente empleada. ${ }^{36}$ Puede tratarse de un error en la fuente, aunque es probable también que la contribución fiscal se encontrara oculta en denominaciones genéricas. ${ }^{37}$

Tamaulipas no registró ingreso fiscal alguno derivado de las exportaciones en los tres años considerados como referencia, aunque seguramente el impuesto sobre fincas rústicas afectaba a muchos terrenos ocupados en

${ }^{34}$ En Tabasco, la importancia de las exportaciones para el erario estatal aumentó considerablemente en los últimos años de la década de 1920. De acuerdo con una obra de la época, los impuestos relacionados con la producción agrícola pasó de "cerca de 10\% de los ingresos del estado" en 1927, a 27.8\% en 1931. Los productos que se gravaban eran el plátano, la copra, el cacao y el café, pero se eximía al plátano que no se destinaba a la exportación. Véase Lazos, "Formas", 1934, pp. 256-258.

${ }^{35}$ Esto es lo que se sugiere en Dobado y Silva, "Crecimiento", 2007, p. 496.

${ }^{36}$ La evidencia a que me refiero es el trabajo de Lazos, "Formas", 1934, que aunque se ocupa particularmente del año de 1931, se refiere con frecuencia a la situación que privaba "para el quinquenio de 1927 a 1931 ”.

${ }^{37}$ Una fuente confiable sugiere que el grueso de los ingresos estatales en el decenio de 1920 provenía de impuestos sobre fincas rústicas, derechos de ventas y contribución directa sobre giros mercantiles e industriales. Vega, Informe, 1925, pp. 29-34. 
actividades de exportación. Sería extraño que las extracciones de maderas y palo de tinte que se realizaban desde una etapa temprana en el área de Tampico no hubieran generado ingresos fiscales, aunque es posible que lo hicieran en el plano municipal. Pero lo que resulta más difícil de creer es que la explotación petrolera que se desplegó en el sur de Tamaulipas a partir de la década de 1910 no hubiera redundado en un beneficio fiscal directo para la Hacienda estatal. De hecho, sabemos que desde 1922 algunos de los impuestos federales con los que se gravaba la explotación petrolera implicaban una participación a los estados y municipios. Así, por ejemplo, del impuesto sobre terrenos y contratos correspondía $20 \%$ a los estados y $20 \%$ a los ayuntamientos, y 5\% del impuesto sobre producción de petróleo crudo y sus derivados. ${ }^{38}$ En la ley de 1925, estas participaciones se modificaron, de manera que se destinó a los estados "no menos" de $10 \%$ del impuesto de producción y 30\% por derecho de superficie en el caso de terrenos baldíos. ${ }^{39}$ Estos ingresos, sin embargo, no aparecen en las entradas del erario estatal en la fuente utilizada, y no disponemos de otra información que permita corroborarla o corregirla.

Algo similar sucede en el caso de Veracruz, que ha sido ubicado en los casos de los incisos $a$ y $c$ debido a que la contribución aparentemente modesta de las exportaciones se debe tanto a la considerable diversificación de su economía (caso $a$ ) como al problema de que las participaciones derivadas de la exportación del petróleo no aparecen en la fuente utilizada en el cuadro (caso c). ${ }^{40}$ No obstante, existen para Veracruz fuentes documentales adicionales que permiten constatar una derrama mayor de las actividades de exportación. En la primera década del siglo $\mathrm{XX}$, una parte de esa derrama se encontraba oculta en el impuesto predial y el derecho de patente, que por lo demás representaban las fuentes más importantes de ingreso para el erario estatal. En 1922, la producción de petróleo aportó más de un millón de pesos a la recaudación y representó el ramo más importante para la Hacienda del estado. ${ }^{41}$ Como no disponemos de datos para 1926, hemos apuntado por separado el porcentaje que esa cifra hubiera representado en los ingresos de ese año $(16 \%)$ a sabiendas de que el dato no corresponde a la realidad, con el propósito de hacer notar la

${ }^{38}$ Kuntz, Exportaciones, 2010, cap. 8, y Diario Oficial, 3 de enero de 1923, p. 18.

${ }^{39}$ Diario Oficial, 31 de diciembre de 1925, p. 894. A mediados de 1926 se estableció en 9\% la participación de los estados, y el 1\% restante para los municipios en que se localizaran los pozos productores. Yáñez, Problema, 1958, t. III, p. 177.

${ }^{40}$ Existe evidencia de que la contribución de las exportaciones agrícolas al erario estatal aumentó en los últimos años de la década, pues pasó de 6\% en 1927 a 12.6\% en 1929. Los productos gravados eran café, naranja, plátano, hule, vainilla y chicle. Lazos, "Formas", 1934, pp. 661-663.

${ }^{41}$ Peña, Veracruz, 1946, p. 484. 
existencia de un ingreso adicional de magnitud importante pero por el momento desconocida.

Finalmente, en el caso de Zacatecas también resulta anómalo que no se registre ingreso alguno originado en las exportaciones, y ni siquiera por concepto de explotación de recursos naturales, puesto que las "participaciones estatales" en los impuestos federales sobre la minería solían incorporarse en la contabilidad de las propias haciendas de los estados. ${ }^{42} \mathrm{Y}$ no es que Zacatecas hubiera dejado de ser un importante productor minero; en 1927 apareció como tercer productor de plata y segundo de plomo a escala nacional. Además, la fuente tampoco registra ingreso alguno por concepto de "productos regionales", pese a que existe evidencia de que el estado gravaba la producción de ixtle y guayule. ${ }^{43} \mathrm{Si}$ bien no podemos cuantificar esos ingresos, informes del gobierno estatal de la década de 1920 reportan el cobro de impuestos sobre la producción de minerales y sobre el corte y beneficio de guayule. ${ }^{44}$

En suma, todo parece indicar que entre los estados que aparentemente obtuvieron del sector exportador ingresos modestos o fluctuantes, hay varios (probablemente seis) que deben esa situación ya sea a una estructura fiscal que carecía de impuestos específicos para las actividades exportadoras pero que se beneficiaban de ellas mediante impuestos genéricos, o bien a fallas en la información disponible. En ambos casos, el resultado es una subestimación del impacto fiscal directo de las actividades referidas y, en algunos, la imposibilidad de cuantificar un ingreso que, no obstante, se adivina significativo.

Por último, encontramos siete casos en los cuales la derrama fiscal directa de las exportaciones fue elevada en al menos dos de los momentos analizados. Se trata de los estados de Campeche, Coahuila, Chihuahua, Durango, Hidalgo, Sonora y Yucatán. Todos ellos fueron exportadores connotados. Según la clasificación ofrecida en el esquema 1, dos (Durango e Hidalgo) pertenecían al subgrupo 1 (de exportadores mineros), dos (Campeche y Yucatán) al subgrupo 2 (de exportadores agropecuarios), y los tres restantes al subgrupo 3 (de las entidades que combinaban ambas especializaciones).

Estos estados no sólo se beneficiaron de una elevada derrama directa de las exportaciones, sino que registraron los ingresos totales más altos en cada uno de los años considerados; en promedio, pasaron de 1.26 pesos (reales) per cápita en 1879-1880 a 2.63 en 1890, 3.68 pesos en 1905 y 37

\footnotetext{
${ }^{42}$ De hecho, así debían hacerlo por ley, o al menos así se especifica claramente en 1926. Véase, por ejemplo, Yáñez, Problema, 1958, t. III, p. 176.

${ }^{43}$ Lazos, "Formas", 1934, pp. 665-667.

${ }^{44}$ Rodarte, Informe, 1927, pp. 16-19.
} 
en 1926. Este desempeño es excepcional incluso respecto al conjunto de los estados exportadores, como se puede apreciar al compararlo con los grupos del cuadro 1. En términos generales debe reconocerse que esta derrama resultó favorable para los estados beneficiados con ella, que por esa razón se encontraron entre los más prósperos del país. No obstante, la importancia del sector exportador para estas entidades pudo haber generado una dependencia excesiva respecto a un solo tipo de actividad (generalmente de origen agrario) y una escasa diversificación de las fuentes de ingreso. A juzgar por su especialización productiva y por la escasez de otras fuentes de ingreso, este parece haber sido el caso de Campeche y, aun en mayor medida, de Yucatán. ${ }^{45}$

En un trabajo reciente, Dobado y Silva consideran que la contribución fiscal de las exportaciones mineras debió haber sido pequeña en razón de la modesta carga tributaria que pesaba sobre ellas $(1.5$ a $2 \%$ del valor de la producción para buena parte del periodo). ${ }^{46}$ No obstante, esa carga fiscal moderada representaba, como se puede apreciar aquí, una contribución importante, a veces crucial, para las dimensiones de las haciendas estatales. En los años utilizados como muestra, los estados mineros de Chihuahua, Hidalgo y Sonora percibieron entre un mínimo de doce y un máximo de $41 \%$ de sus ingresos por ese concepto. Coahuila y Durango ofrecen cifras menos llamativas, pero en cualquier caso notables. A esta contribución significativa en el plano de las finanzas estatales se sumaban, adicionalmente, otras dos derramas fiscales importantes. Por un lado, la que la propia minería arrojaba a escala federal; por el otro, la que la industria metalúrgica aportaba en el ámbito municipal.

\section{CONCLuSiones}

$\mathrm{El}$ acercamiento que hemos ofrecido en este trabajo posee al menos dos limitaciones. Por un lado, ofrece retratos estáticos de apenas tres o cuatro momentos dentro de los cincuenta años que abarcó la primera era exportadora de México. Incluso si, como suponemos, los años empleados son representativos de un fenómeno más general, queda por saber cuál fue el comportamiento año con año de las finanzas estatales. Así, este acercamiento no nos habilita para saber si la dependencia respecto a las exportaciones sujetó a los gobiernos estatales a altibajos perjudiciales para la vida de sus entidades. Por el otro, no profundiza en el análisis de cada uno de los estados involucrados, pues la perspectiva se mantiene generalmente en un plano panorámico en

${ }^{45}$ Aboites, Excepciones, 2003, p. 75.

${ }^{46}$ Dobado y Silva, "Crecimiento", 2007, p. 496. 
el que destacan solamente algunas regularidades y comportamientos para grupos diferenciables dentro del conjunto, ofreciendo apenas un breve acercamiento a las circunstancias de algunos estados.

No obstante estas limitaciones, nuestro análisis ha ofrecido pruebas sólidas de que la contribución de las exportaciones a las finanzas estatales fue positiva y a veces considerable. En primer lugar, el análisis de indicadores básicos sobre la evolución de las finanzas estatales nos permitió demostrar un desempeño claramente diferenciado según el carácter de exportadores o no exportadores de los distintos estados, y dentro del primer grupo, según la especialización exportadora de cada uno de ellos. En todos los casos observados, las finanzas de los estados exportadores se comportaron mejor que las de los no exportadores. Además, los erarios de estados dedicados a exportaciones agrícolas tuvieron un mejor desempeño que los de especialización minera. Atribuimos este comportamiento tanto a la doble o triple imposición que enfrentaban los productos mineros como a la más tardía federalización de los impuestos sobre actividades agrícolas, sin excluir la posibilidad de que en algunos casos hubiera una mayor propensión a gravar productos agrícolas con escaso nivel de elaboración.

En un segundo plano de análisis, nos ocupamos de la derrama directa de las exportaciones a las finanzas de los estados, es decir, de los impuestos específicamente destinados a gravar actividades exportadoras y su comportamiento en los distintos momentos. En este ámbito encontramos también grados diversos de contribución, dependiendo probablemente de factores tales como la capacidad y estructura tributaria de cada estado y el éxito relativo de las propias actividades exportadoras. En al menos siete estados con diversas áreas de especialización dentro del sector exportador la derrama fiscal directa de las exportaciones fue elevada y consistente, a juzgar por las cifras que arrojan los años considerados. En cinco, una contribución más modesta se relaciona con una menor importancia del sector exportador y con economías más diversificadas en el plano estatal. En otros seis la información es insuficiente para hacer una valoración más precisa, aunque las piezas de evidencia disponibles sugieren que la aportación de las exportaciones fue positiva y, al menos en algunos casos, significativa. En muy pocos casos se observa una magra contribución de las exportaciones a los erarios estatales, y en ellos el fenómeno se asocia al pobre desempeño de las actividades exportadoras, más que a una escasa retribución por parte de actividades de otra manera exitosas. En conjunto, pues, este primer acercamiento ofrece una visión optimista de la contribución económica de las exportaciones desde el punto de vista de las finanzas estatales, si bien esta valoración preliminar debe ser confirmada, matizada o desmentida por investigaciones futuras. 


\section{Fuentes CONSUlTADAS}

\section{Archivos}

AGEY Archivo General del Estado de Yucatán, Mérida, México.

\section{Hemerografía}

Diario Oficial, ciudad de México, México.

\section{Bibliografía}

AвоITEs, Luis, Excepciones y privilegios. Modernización tributaria y centralización en México, 1922-1972, México, El Colegio de México, 2003.

Chassen-LóPez, Francie R., Oaxaca. Entre el liberalismo y la revolución. La perspectiva del sur (1867-1911), Oaxaca, Universidad Autónoma de México/Universidad Autónoma Benito Juárez de Oaxaca, 2010.

Crespo, Horacio, Historia del azúcar en México, México, Fondo de Cultura Económica, 1988.

"Un nuevo modelo en la industria azucarera. Reforma agraria y decretos cañeros de 1943-1944" en Horacio Crespo (dir.), Historia de Morelos. Tierra, gente, tiempos del Sur, Cuernavaca, Congreso del Estado de Morelos, 2011, t. VI, pp. 385-400.

Departamento de la Estadística Nacional (DEN), Algunos cuadros sintéticos de estadísticas de México, México, 1929.

Díaz Cayeros, Alberto, Political Responses to Regional Inequality: Taxation and Distribution in Mexico, Durham, Duke University, 1997.

Dobado, Rafael y Sergio Silva Castañeda, "Crecimiento minero impulsado por las exportaciones en regiones de México y España (1868-1913)" en RAFAEL DobAdo, Aurora Gómez y Graciela Márquez (comps.), México y España. ¿Historias económicas paralelas?, México, Fondo de Cultura Económica, 2007, pp. 471-506 (Lecturas de El Trimestre Económico, núm. 98).

El Colegio de MéXico, Estadísticas económicas del porfiriato. Fuerza de trabajo y actividad económica por sectores, México, El Colegio de México, 1960 [1961?].

GÁmeZ, MoIsés, "Prácticas impositivas y de fomento en la minería mexicana: San Luis Potosí, 1870-1920” en Moisés GÁmez y Javier PÉrez Siller (coords.), La fiscalidad en la construcción del Estado nacional. Guanajuato, San Luis Potosí y Tamaulipas, 1824-1910, San Luis Potosí, El Colegio de San Luis, 2012, pp. 125-167. 
Gómez-Galvarriato, Aurora y Aldo Musacchio, "Un nuevo índice de precios para México, 1886-1929”, El Trimestre Económico, año LXVII, núm. 1 (265), eneromarzo de 2000, pp. 47-91.

Gómez Serrano, Jesús, Aguascalientes: imperio de los Guggenheim, México, Fondo de Cultura Económica, 1982 (sEP/80, 43).

Hirschman, Albert O., "El desarrollo desde el punto de vista de los enlaces generalizados, con referencia especial a los bienes básicos” en Albert O. Hirschman, De la economía a la política y más allá: ensayos de penetración y superación de fronteras, México, Fondo de Cultura Económica, 1984.

Instituto Nacional de Estadística, Geografía e Informática (InEGi), Estadísticas históricas de México, México, Instituto Nacional de Estadística, Geografía e Informática, 5a. ed., 2009.

JÁuregui, Luis, "Vino viejo y odres nuevos. La historia fiscal en México", Historia Mexicana, El Colegio de México, año LII, núm. 3 (207), enero-marzo de 2003, pp. 725-771.

Kuntz Ficker, SANDRA, Las exportaciones mexicanas durante la primera globalización, 1870-1929, México, El Colegio de México, 2010.

LAZOS, HÉCTOR, "Formas en que los impuestos locales gravan la agricultura" en PARTIdo Nacional Revolucionario, Los problemas agrícolas de México, México, Secretaría de Acción Agraria, 1934.

Ministerio de Fomento, Anales del Ministerio de Fomento de la República Mexicana, México, 1881, t. V.

NAVArro, Ignacio, "El sistema fiscal mexicano" en Ignacio NAVArro et al., Estudios para la reforma del sistema fiscal de la república, México, Cultura, 1927.

O’Gorman, Edmundo, Breve historia de las divisiones territoriales. Aportación a la historia de la geografía de México, México, Polis, 1937.

Peña, Moisés T. DE LA, Veracruz económico, México, Gobierno del Estado de Veracruz, 1946, t. II.

Riguzzi, PAOLO, "El difícil camino hacia la modernidad: la Hacienda pública del Estado de México, 1870-1923” en Carlos Marichal, Manuel Miño Grijalva y PAOlo RiguzZI, El primer siglo de la Hacienda pública del Estado de México, 1824-1923, México, El Colegio Mexiquense/Gobierno del Estado de México, 1994, t. I.

"Mercados, regiones y capitales en los ferrocarriles de propiedad mexicana, 1870-1908” en SAndra Kuntz Ficker y Priscilla Connolly (coords.), Ferrocarriles y obras públicas, México, Instituto de Investigaciones Dr. José María Luis Mora/El Colegio de Michoacán/El Colegio de México/Universidad Nacional Autónoma de México, 1999.

Rodarte, Fernando, Informe administrativo del gobernador constitucional de Zacatecas $C$. Fernando Rodarte ante la XXIX Legislatura del estado, Zacatecas, Talleres de la Escuela Industrial, 1927.

Romero Sotelo, María Eugenia y Ángeles Cortés Basurto (coords.), Comisión Monetaria, Actas de las Juntas Generales y documentos a ellas anexos. Reforma monetaria 
de 1905, México, Universidad Nacional Autónoma de México, 2007 (publicado originalmente en Secretaría de Hacienda y Crédito Público, Memoria de Hacienda y Crédito Público correspondiente al año económico: $1^{\circ}$ de julio de 1903 a 30 de junio de 1904, México, Tipografía de la Oficina, Impreso de Estampillas, Palacio Nacional, 1909, p. 718).

Secretaría de Hacienda y Crédito Público (shCP), Memoria de Hacienda y Crédito Público correspondiente al año económico: $1^{\circ}$ de julio de 1903 a 30 de junio de 1904, Comisión monetaria. Actas de las Juntas Generales y documentos a ellas anexos. Documento número 159, México, Tipografía de la Oficina, Impreso de Estampillas, Palacio Nacional, 1909, p. 718.

, La Hacienda pública de los estados, México, 1911, 2 vols.

, Primera Convención Nacional Fiscal. Memoria, México, Secretaría de Hacienda y Crédito Público, 1926.

SERVín, Armando, Las finanzas públicas locales durante los últimos cincuenta años, México, Secretaría de Hacienda y Crédito Público, 1956 (Serie de Trabajos Monográficos de la Dirección General de Estudios Hacendarios, núm. 1).

UHTHOFf LÓPEz, LUZ MARÍA, Las finanzas públicas durante la revolución: el papel de Luis Cabrera y Rafael Nieto al frente de la Secretaría de Hacienda, México, Universidad Autónoma de México, 1998.

"Los impuestos al comercio exterior en México en la era de las exportaciones, 1872-1930", América Latina en la Historia Económica, Instituto de Investigaciones Dr. José María Luis Mora, núm. 24, julio-diciembre de 2005, pp. 7-36.

Vega, Alejandro R., Informe de gobierno correspondiente al año comprendido del 16 de septiembre de 1924 al 15 de septiembre de 1925, rendido por el ciudadano Alejandro R. Vega, gobernador constitucional del Estado de Sinaloa, ante la 31a Legislatura local, Culiacán, Imprenta del Gobierno del Estado de Sinaloa, 1925.

Velasco Ávila, Cuauhtémoc et al., Estado y minería en México (1767-1910), México, Secretaría de Energía, Minas e Industria Paraestatal/Instituto Nacional de Antropología e Historia/Fondo de Cultura Económica, 1988.

YÁÑEz RuIZ, MANUEL, El problema fiscal en las distintas etapas de nuestra organización política, México, Secretaría de Hacienda y Crédito Público, 1958, t. III.

Zuleta, Cecilia, "Hacienda pública y exportación henequenera en Yucatán, 18801910”, Historia Mexicana, El Colegio de México, vol. 54, núm. 1 (213), julio-septiembre de 2004, pp. 179-247.

De cultivos y contribuciones. Agricultura y Hacienda estatal en México en la "época de la prosperidad”. Morelos y Yucatán 1870-1910, México, Universidad Autónoma de México, 2006.

, “¿Agridulces contribuciones? Azúcar y Hacienda pública en Morelos decimonónico" en Horacio Crespo (dir.), Historia de Morelos. Tierra, gente. Tiempos del Sur, t. ViII: María Victoria Crespo y Luis Anaya Merchant (coords.), Politica y sociedad en el Morelos posrevolucionario y contemporáneo, Cuernavaca, Congreso de Morelos, LI Legislatura, 2011, pp. 589-616. 